\section{FIRST MARBLED MURRELET RECORD FOR ALBERTA}

The Marbled Murrelet carcass pictured below was found by the author on the shore of Saskatoon Lake (NE/6-72-7w6) on 8 July 1994. No apparent cause of death could be determined. The carcass was forwarded to the Alberta Provincial Museum in Edmonton where it now resides as a skin.

- Gavin Moore, RR\#1, Wembley, AB.

\section{A DIFFERENT DRUMMER}

The author has analyzed the crazy-flight phenomenon of the Ruffed Grouse in several articles, including nine grouse collisions with our farm home in the 1960s and 1970s. ${ }^{2,3,4,5,6,7}$ The conclusion was that more than a dozen distinct conditions may contribute to the flight or even initiate it but they are always complemented by the underlying reason - the grouse's natural rocketing take-off and limited manoeuvrability. After a hiatus of 20 years, another grouse collided with the same house, and survived.

On 25 May 1995, shortly after 9:00 p.m. (the sun had already set), I entered our vacated, darkened farm house, three miles east of Rosthern. Scatter rugs askew on the livingroom floor caught my attention, but not nearly as much as some movement up a far wall in the semidarkness. I was thinking "raccoon," but the fan-shaped tail identified the creature as yet another Ruffed Grouse.

I immediately went out, rather gingerly, not wishing to agitate the grouse into making a further "crazy" flight within the house. I left the living-room door and outer porch door open for its departure. My examination of the house's exterior revealed that the bird had gained entrance

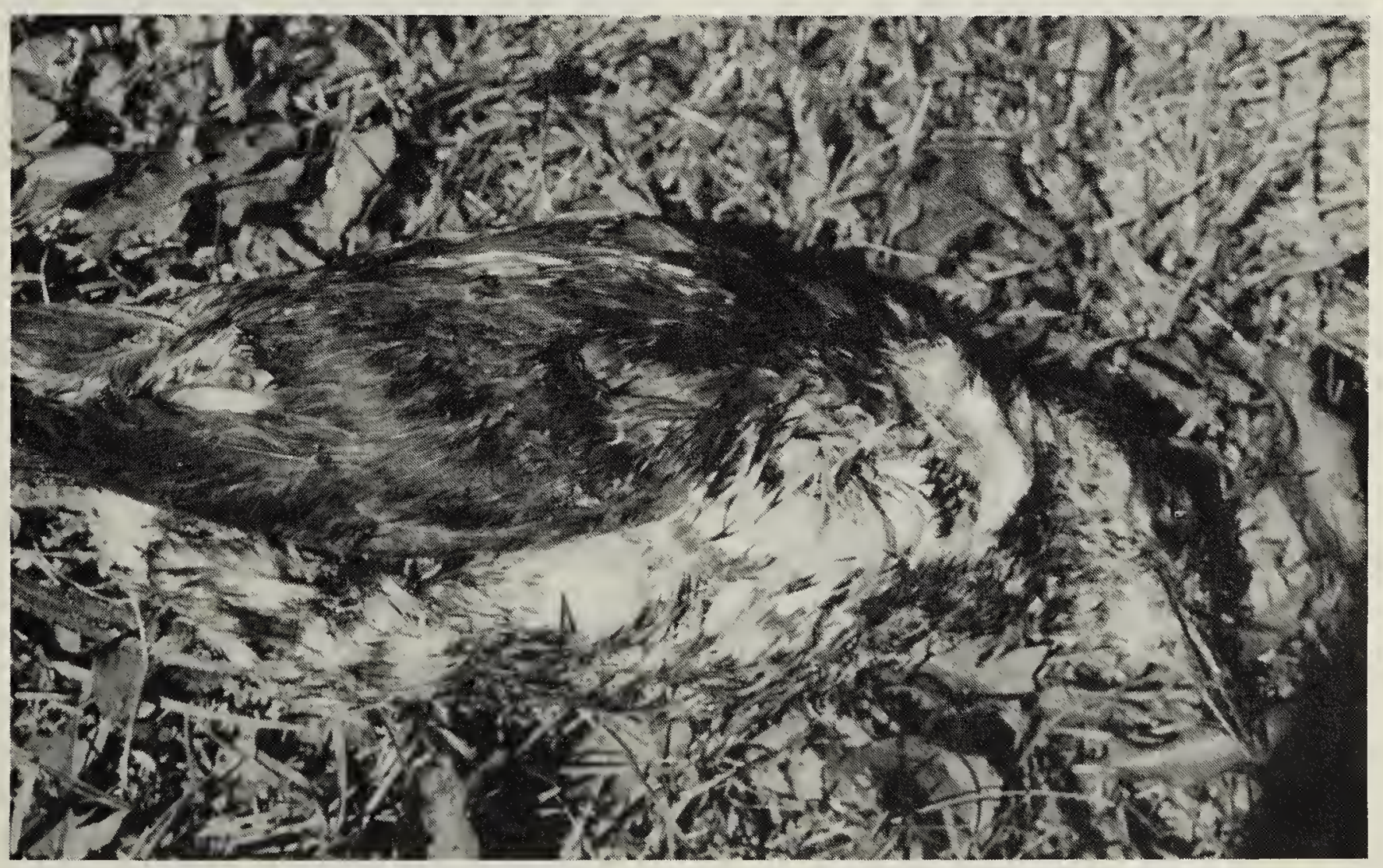

Marbled Murrelet carcass found at Saskatoon Lake, $A B$

Dave Robertson 